\title{
Study on the Virtual Value Chain of Civil Aviation Transportation Industry under E-Commerce Environment
}

\author{
Dong Lu
}

Shanghai Civil Avation College, Shanghai 200232, China.

\begin{abstract}
With the development of society and the continuous progress of science and technology, the business environment is constantly changing. Among them, the civil aviation transportation industry is a relatively special case. In the traditional value chain, the civil aviation transportation industry is not flexible compared with other professions. Therefore, at the beginning of the formation of the virtual value chain in the e-commerce environment, the civil aviation transportation industry should overcome some difficulties in the traditional value chain. This is the purpose of this paper. This paper will take the meaning of the virtual value chain as the entry point to analyze the theory of the traditional value chain of the civil aviation transport industry, so as to explore how to build the virtual value chain of the civil aviation transport industry and summarize the characteristics of the virtual value chain of the civil aviation transport industry.
\end{abstract}

Keywords: e-commerce; civil aviation transport industry; Virtual value chain.

\section{Introduction}

The theory of virtual value chain is based on the traditional value chain. At that time, foreign scholars have made a deep comparison between the virtual value chain and the traditional value chain, and at the same time, made a deep study of its significance. At present, this research is usually confined to manufacturing industry. This paper focuses on the study of the virtual value chain of civil aviation transportation industry. Different from manufacturing industry, civil aviation transportation industry is the service industry of the tertiary industry, which is also greatly changed in the context of e-commerce. Therefore, the significance of research and discussion on it is also crucial.

\section{The Meaning of Virtual Value Chain}

As mentioned above, the concept of virtual value chain originated in the 1990s. Its significance is that traditional value chain is formed in the real world, and then a new form of value chain is formed in the virtual world. Therefore, it must have a carrier, and the e-commerce environment just provides it a suitable, generous carrier. In the past management work, the virtual value chain is often used as an auxiliary means of the traditional value chain. When coming to the current environment of ecommerce, virtual value chain is often able to produce independently due to its characteristics. And its characteristics include: non-materiality, flexibility, uniqueness and persistence. Its features are described below, and are expressed in model form for clarity, as shown in Table 1.

Table 1. Virtual value chain indication

\begin{tabular}{|c|c|c|c|c|}
\hline $\begin{array}{c}\text { Information technology } \\
\text { platform }\end{array}$ & $\begin{array}{c}\text { Intellectual } \\
\text { capital, }\end{array}$ & $\begin{array}{c}\text { Third party } \\
\text { logistics }\end{array}$ & $\begin{array}{c}\text { Technology } \\
\text { development }\end{array}$ & $\begin{array}{c}\text { Online } \\
\text { purchase }\end{array}$ \\
\hline \multicolumn{4}{|c|}{ The Online supply management } \\
\hline \multicolumn{3}{|c|}{ Virtual production } \\
\hline \multicolumn{3}{|c|}{ The Online inventory management } \\
\hline \multicolumn{3}{|c|}{ The Online services } \\
\hline
\end{tabular}

By analyzing the value chain, we find that the virtual value chain indeed has the above four characteristics. First of all, in the aspect of non-materiality, the embodiment form is often reflected in the virtual environment such as the network, so it is less constrained by the traditional aspects such as land and labor force [1]. In terms of flexibility, it can be reflected from two aspects. Firstly, enterprises have very flexible control over information. Moreover, different from traditional value chains, virtual value chains can provide customers with more intensive value-added points of 
information. In terms of uniqueness, information itself is different and has different use value. The same information has no value in the eyes of other enterprises. Therefore, virtual value chain has certain uniqueness. Finally, in terms of persistence, no matter it is traditional value chain or virtual value chain, it cannot be regarded as a combination of technologies, and it should be formed through continuous precipitation in the development process of enterprises. Such kind of precipitation sense cannot be imitated, and it is precisely because of this difficult personality that the persistence of its virtual value chain is caused.

\section{Traditional Value Chain of Civil Aviation Transportation Industry}

In the traditional value chain of civil aviation transportation industry, as the core of the natural is Ming shipping transport business. Therefore, in the upper part of the traditional value chain are the enterprises and merchants that manufacture aircraft, buy and sell aircraft, provide flight service and airport service. The off-duty part of the value chain is the channel business, which is mainly engaged in freight service and passenger service, so as to obtain profits in this form. The specific form will be expressed in the form of chart, for details see figure 1.

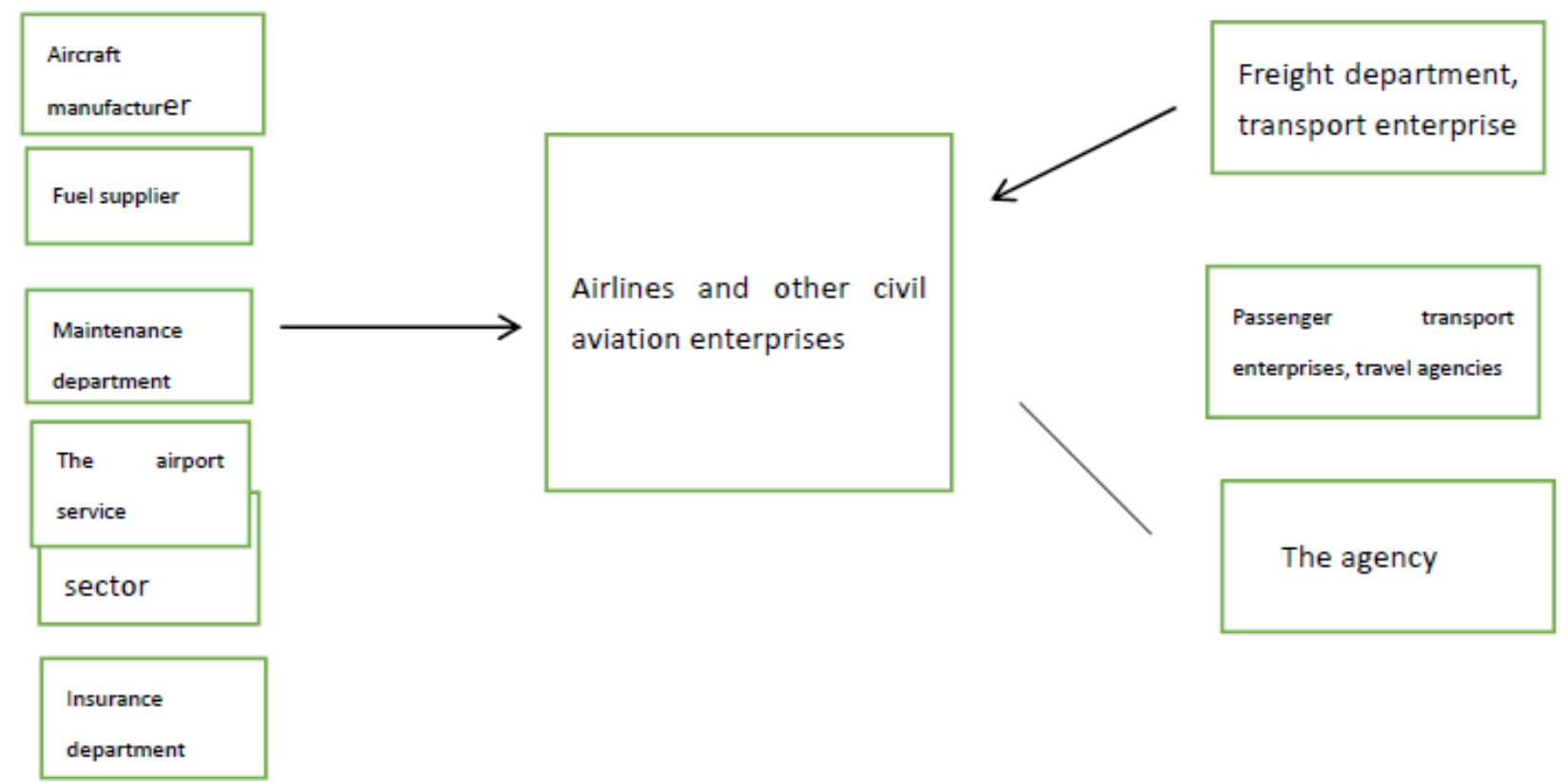

Figure 1. In the traditional value chain of civil aviation transportation industry

In figure 1, the solid line with arrow means capital flow and logistics, while the solid line without arrow means passenger flow. From this, we can see that all business of civil aviation company is focused on service, so its product strength is mainly reflected in the quality of service. The aircraft manufacturer, fuel supplier, maintenance department, etc. in the upstream of the value chain constitute the main body, which focuses on the aircraft flight business. In terms of downstream and downstream freight departments and passenger transport enterprises, they are more concerned about how to achieve performance through services, and their focus is only to reach the level of services. The lack of communication between the upstream and downstream leads to a lack of choice in the process of customer service [2].

\section{Constructing the Virtual Value Chain of Civil Aviation Transportation under the E-commerce Environment}

Information technology is making constant progress at the moment, and the globalized network necessary for the e-commerce environment is being perfected at the same time. In this paper, we hope to build the value chain in such an environment, namely the virtual value chain of civil aviation 
transportation industry. Based on the traditional value chain, the civil aviation transportation industry of virtual value chain not only transport business as the core, but as auxiliary air traffic information system, comprehensive information statistics in addition to the airport, the airport agent and freight system has changed, the past capital chain up and down between the block is broken, its contact nature become more closely, to ensure that the information transfer more smoothly, discrepancy and less content.

\section{The Characteristics of the Virtual Value Chain of Civil Aviation Transportation Industry}

\subsection{Obtain Value Through Information}

Tourism is a very important part of the civil aviation transportation industry. In the past, the meaning of information in the value chain was only seen as a value-added function, which could not directly produce value. However, in the coming environment of e-commerce, the tourism industry has also undergone tremendous changes. The value of information has its auxiliary role in the past, which is directly transformed into the main source of value. Through advanced electronic technology, the connection of the upper and lower value chains can be made closer, and both the personnel information and the departure of the flight can be transmitted more intuitively. For example, the faster information is transmitted, the closer the integration of the upper and lower sectors of the value chain.

\subsection{Reduction}

When the emergence of virtual value chain plays some role in the traditional value chain, the artificial has been replaced to some extent through such means. This situation makes the necessary links in the traditional value chain do not exist at present. Therefore, compared with the traditional value chain, the virtual value chain of the civil aviation transportation industry is naturally shorter in the link. For example, in the traditional value chain, ticket sales often occur due to the information asymmetry, which requires many times of resale to be purchased by passengers. However, after the rise of e-commerce, passengers can purchase tickets directly through the network, so the ticket sales company only needs to provide a virtual platform to sell several articles to people in need. In this process, the steps have been greatly reduced, which not only reduces the sales cost, but also improves the efficiency.

\subsection{Customer Focus}

In the past, information was not flexible enough in the traditional value chain of the civil aviation transportation industry. This makes the message not only slow, but often single-phase. As a result, the civil aviation transportation industry has no way to develop personalized services for customers according to their needs. Customers can only comply with all the arrangements of the airport in the process of entering the airport for check-in and boarding [3]. But the airline industry is a service industry that should aim to provide the best user experience for its customers. The virtual value chain of the civil aviation transportation industry can understand the real needs of users, formulate different service plans through the analysis of information, and propose more choices for customers. In this way, customers can not only enjoy comfortable service, but also generate a lot of extra profits, so that the upper and lower parts of the value chain can gain more economic benefits.

\subsection{Competition Tends to be Diversified}

In the current e-commerce environment, the competition between major airlines has become more intense. Competition in the past was limited to the competition of customers, but now it has spread to the competition of market information. In the virtual value chain, information becomes more flexible than in the past, and the direction of information exchange becomes two-way. For example, when the number of passengers reaches a certain number, they often choose to contact the airlines and skip the restriction of ticket selling enterprises. In addition, as a result of this situation, the 
convenience of the subordinate business of each enterprise becomes less clear. Such a competitive environment is the beginning of a virtuous cycle and also the key to the development of related enterprises.

Conclusion: through the discussion of this paper, we find that the overall environment of ecommerce has become more and more complete, and all industries will be affected by the overall environment. E-commerce makes information transfer more rapidly, so the overall pattern of the civil aviation transportation industry has undergone a great change, which will naturally lead to changes in its value chain. The virtual value chain of civil aviation transportation industry is based on the traditional value chain to realize the goal of improving enterprise competitiveness and fully reflecting the value of the information age. So, we need to be ready to face the challenge again and again, to make it work.

\section{References}

[1]. Huang wei, zhu aiping. Study on the virtual value chain of civil aviation transportation industry in the context of e-commerce [J]. Business accounting, 2017(16): 23-25.

[2]. Huang wei. Study on value chain cost management of China's civil aviation transportation industry [D]. Jimei University, 2018.

[3]. Long huijun. Research on virtual value chain [D]. Kunming University of science and technology, 2006. 